\title{
FORMAÇÃO DE PROFESSORES: O CASO “CIRANDA DIGITAL DA CIDADANIA” DO LIM/LIFE-UEG
}

\author{
Mylena Seabra Toschi ${ }^{1}$ \\ https://orcid.org/0000-0002-8775-2939 \\ Yara Fonseca de Oliveira e Silva ${ }^{2}$ \\ https://orcid.org/0000-0001-5725-478X
}

\begin{abstract}
Resumo: Este estudo apresenta o projeto de extensão "Ciranda Digital da Cidadania”, sobre a inclusão digital de idosos a partir do trabalho desenvolvido no Laboratório de Mídias Interativas/Laboratório Interdisciplinar de Formação de Educadores (LIM/LIFE) da Universidade Estadual de Goiás (UEG). O estudo objetiva refletir sobre o processo formativo com base na abordagem da subjetividade e se desenvolveu por meio de observação e entrevistas semiestruturadas com professoras-bolsistas do curso de pedagogia da UEG. O processo formativo com base na abordagem da subjetividade rompe com a visão dicotômica teoria-prática e supera a fragmentação do conhecimento por valorizar a dialogicidade, a reflexão crítica e colaborativa.
\end{abstract}

Palavras-chave: Formação de professores. Inclusão digital do idoso. Subjetividade. Universidade Estadual de Goiás. Extensão.

\section{TEACHER TRAINING: THE “CIRANDA DIGITAL DA CIDADANIA” CASE OF LIM/LIFE-UFG}

Abstract:This study presents the extension project "Ciranda Digital da Cidadania" (Digital Ciranda of Citizenship) from the digital inclusion of the elderly, in the Interactive Media Laboratory/Interdisciplinary Laboratory of Teacher Training (LIM/LIFE), from the State University of Goias (UEG). The study aims to reflect on the training process, based on the subjectivity

1 Professora da Associação Educativa Evangélica (AEE). Mestre do Programa de Pós-Graduação Interdisciplinar em Educação, Linguagem e Tecnologias da Universidade Estadual de Goiás (PPGIELT-UEG). E-mail: mstoschi@hotmail.com

2 Professora do Programa de Pós-Graduação Interdisciplinar em Educação, Linguagem e Tecnologias da Universidade Estadual de Goiás (PPGIELT-UEG). Doutora em Políticas Públicas, Estratégias e Desenvolvimento (IE-UFRJ). E-mail: yarafonsecaso9@gmail.com 
approach and was developed through observation and half-structured interviews with female teachers with scholarships in the UEG Pedagogy course. The training course, based on the subjectivity approach, breaks the dichotomic view of theory and practice, and overcomes the fragmentation of knowledge, by valuing the dialogue, and the critical and collaborative reflection.

Keywords: Teacher training. Digital inclusion of the elderly. Subjectivity. State University of Goias. Extension.

\section{FORMACIÓN DE PROFESORES: EL CASO “CIRANDA DIGITAL DA CIDADANIA” DEL LIM/LIFE/UFG}

Resumen: Este estudio presenta el proyecto de extensión Ciranda Digital da Cidadania (Ciranda Digital de la Ciudadanía), sobre la inclusión digital de ancianos a partir del Laboratorio de Medios Interactivos/Laboratorio Interdisciplinario de Formación de Educadores (LIM/LIFE) de la Universidad Estadual de Goiás (UEG). El estudio objetiva la reflexión sobre el proceso formativo con base en el abordaje de la subjetividad y se desarrolló por medio de observación y entrevistas semiestructuradas con profesoras bolsistas del curso de pedagogía de la UEG. El proceso formativo, basado en el abordaje de la subjetividad, rompe con la visión dicotómica teoría-práctica y supera la fragmentación del conocimiento por valorar el diálogo, la reflexión crítica y colaborativa.

Palabras clave: Formación de Profesores. Inclusión digital de ancianos. Subjetividad. Universidad Estadual de Goiás. Extensión.

Submetido em: 05/10/2018

Aceito em: 05/11/2018

\section{INTRODUÇÃO}

Este estudo reflete a experiência do projeto de extensão que trata da inclusão digital de idosos, "Ciranda Digital da Cidadania" desenvolvido com a estrutura do Laboratório de Mídias Interativas/Laboratório Interdisciplinar de Formação de Educadores (LIM/LIFE) da Universidade Estadual de Goiás (UEG). Esse projeto de extensão propôs por meio de oficinas de inclusão digital, analisar o desempenho de idosos com diferentes níveis de letramento em relação ao acesso e ao conhecimento mediado pelas tecnologias digitais, analisando a autonomia e capacidade dos idosos de serem multiplicadores da inclusão digital. O LIM/LIFE foi concebido com o compromisso de formar professores aptos a lidar com a complexidade da questão "inclusão digital e social", no sentido de abarcar as necessidades dos aprendentes, considerando os novos ordenamentos estruturais do mundo contemporâneo que envolve os aspectos econômicos, políticos, sociais, culturais, educacionais e das subjetividades pessoais e coletivas. 
O estudo objetiva refletir sobre a formação de professores com base na abordagem da subjetividade ${ }^{3}$. Escolheu-se estudar a abordagem da subjetividade no projeto "Ciranda Digital da Cidadania" por ser um dos poucos momentos em que a indissociabilidade entre ensino, pesquisa e extensão faz-se presente na universidade e por este ser um espaço onde nota-se a presença da integração teórico-prática. O problema buscou desvelar, em que medida a formação de professores com base na abordagem da subjetividade promove (ou não) a inclusão digital com o idoso? Esse estudo é o resultado parcial de um estudo de caso de natureza qualitativa.

Os dados foram coletados por meio de observação dos encontros da equipe e das oficinas de inclusão digital, entrevistas semiestruturadas com as quatro professoras-bolsistas $^{4}$ que participaram das oficinas de aprendizagem desse projeto. Buscou-se compreender as interferências da abordagem da subjetividade do professor em seu processo formativo. $\mathrm{O}$ momento inicial de coleta foi realizado com observações das reuniões da equipe da pesquisa e das oficinas de inclusão digital. Foram observadas oito reuniões da equipe e 23 oficinas - de agosto de 2015 a julho de 2016. As reuniões da equipe de pesquisa eram semanais e foram acompanhadas buscando-se compreender o tipo de relação que se estabelecia entre as professoras-bolsistas e a coordenação. Em um segundo momento foram realizadas entrevistas semiestruturadas com as professoras-bolsistas participantes das oficinas. A seguir apresenta-se o resultado e análise da discussão.

Este capítulo apresenta-se em três seções, além desta introdução e das considerações finais. A primeira apresenta a relação entre a indissiociabilidade ensino-pesquisa-extensão e a formação de professores, a segunda traz

3 Neste trabalho a denominação de subjetividade e a sua abordagem é a defendida por Leite e Dimenstein (2002) que, a partir de autores do pensamento filosófico contemporâneo como Foucault, Deleuze e Guattari concebem a subjetividade como categoria processual, inscrita no plano de sua produção em função dos agenciamentos de instâncias de subjetivação dispostas no registro do social. Tal perspectiva leva a um rompimento com as posturas naturalizantes e individualizantes de abordagem da subjetividade destacando a inseparabilidade entre os processos subjetivos e o campo social. Esses autores enfatizam que a abordagem da subjetividade permite acessar as formas pelas quais os humanos se relacionam com os regimes de verdades de sua época e como podem não só reproduzir tais regimes, mas também reconstruí-los.

4 Essas professoras em processo de formação inicial em nível superior do curso de Pedagogia da UEG, sendo bolsistas do projeto analisado, exercendo a função de educadoras e estando, portanto, em contato direto com os idosos nas oficinas de inclusão digital. Neste estudo, essas professoras em formação e bolsistas da pesquisa serão denominadas professoras-bolsistas. 
a integração teórico-prática e a abordagem da subjetividade na formação docente, a terceira mostra os resultados e a análise da pesquisa.

\section{A UNIVERSIDADE E A FORMAÇÃO DE PROFESSORES}

O eixo fundamental da Universidade brasileira é o tripé formado pelo ensino, pesquisa e extensão, o qual não pode ser compartimentado conforme dispõe o artigo 207 da Constituição Brasileira de 1988 que "as universidades [...] obedecerão ao princípio da indissociabilidade entre ensino, pesquisa e extensão". Equiparadas, essas funções básicas merecem igualdade em tratamento por parte das instituições de ensino superior, que, do contrário, violarão o preceito legal.

Moita e Andrade (2009) afirmam que a universidade tem sido palco de análises e debates que têm dado destaque seja ao ensino, seja à pesquisa, seja ainda à extensão. Entretanto, os autores afirmam que a indissociabilidade entre ensino, pesquisa e extensão ainda não é uma orientação reconhecida sistematicamente na educação superior, permanecendo como um ideal a ser perseguido: o modelo universitário muitas vezes praticado na educação superior ainda é aquele próprio do momento de afirmação e consolidação do saber científico, típico de uma estrutura ainda não eminentemente dialogal.

Ducatti-Silva e Zanon (2014) afirmam que dentre os desafios contemporâneos na formação inicial e continuada de professores, evidencia-se o aspecto relativo à função da universidade: fomentar o diálogo entre ensino, pesquisa e extensão e, entre esses e o campo de atuação do professor. Essas autoras defendem que há uma dinâmica de retroalimentação do ensino e da pesquisa por meio da extensão, ou seja, por meio da aproximação dos acontecimentos materializados na sociedade é que se faz ensino, que se faz pesquisa. Portanto, ensinar pela pesquisa e pela extensão significa buscar a aproximação entre os três componentes. Sabendo-se da dimensão do papel da docência na educação superior é possível depreender que não se faz ensino, depois pesquisa e depois extensão, ou vice-versa, mas os desenvolvimentos desses processos ocorrem concomitantemente.

Ducatti-Silva e Zanon (2014) afirmam ainda que a formação de professores amparada pela indissociabilidade ensino-pesquisa-extensão instigam os acadêmicos a observar aspectos sobre a dimensão didática do trabalho docente, práticas pedagógicas bem sucedidas, como se caracterizam o saber e o 
aprender na docência e rompem com o hiato entre teoria e prática por meio da efetivação do vínculo entre universidade e sociedade.

$\mathrm{Na}$ integração ensino-pesquisa-extensão, o professor se reconhece como pesquisador, no sentido de compreender que quando o professor investiga o que ensina, este processo possibilita a descoberta, o reconhecimento da importância do saber científico, permite ainda investigar a prática pedagógica, gerando interrogações e novas descobertas. A formação de professores apresenta-se como um fenômeno complexo e diverso sobre o qual "o conceito formação inclui uma dimensão pessoal de desenvolvimento humano global que é preciso ter em conta face a outras concepções eminentemente técnicas" (GARCÍA, 1999, p. 21). A dimensão pessoal no processo de formação, as possibilidades e proposições para a formação requerem um olhar atento dos formadores, no sentido de articular as diferentes dimensões que compõem os caminhos formativos dos futuros professores, um processo que perpassa a vida do profissional e não somente ações estanques e isoladas.

A UEG tem sido desafiada a desempenhar seu papel de alcançar a indissociabilidade entre ensino, pesquisa e extensão e consequentemente, a articulação entre teoria e prática em cursos de formação de professores. Ainda que conforme Silva (2014), a UEG atue com maior intensidade nas atividades de ensino e com menor intensidade nas atividades de pesquisa e extensão pois, no decorrer de sua evolução, assumiu mais o papel de difusora do conhecimento e menos o de criadora de conhecimento. Porém, a indissociabilidade é necessária e quando efetivada por meio do vínculo entre universidade e sociedade promove uma formação privilegiada.

O olhar do diálogo se fez presente no projeto "Ciranda Digital da Cidadania" desenvolvido com a estrutura do LIM/LIFE, em que se propunha o alcance da indissociabilidade ensino-pesquisa-extensão. Projetos como esse fazem parte da formação inicial de professores e é importante por colocar o acadêmico em contato com a docência e com as aspirações reais da comunidade, levando-o, como afirma Freire (1996), a realizar uma reflexão sobre a aventura docente. Projetando-se como futuro professor, o discente compreende a prática educativa como processo de criação, envolvimento e conhecimento de diferentes saberes que interagem com o imaginário e o inusitado presente no fazer docente. 


\section{A FORMAÇÃO DE PROFESSOR E AS DIMENSÕES AFETIVA E COGNITIVA}

As vivências dos cursos de formação de professores precisam conferir aos discentes a busca constante pela teoria acadêmica, a capacidade crítica e a reflexão sobre a sua prática. A contemporaneidade é palco de profundas reflexões, modificando a forma de pensar e conceber o homem, o mundo, as coisas. As intensas discussões sobre os limites do rigor científico coloca em xeque a hegemonia do paradigma clássico, modelo de racionalidade herdado a partir do século XVI e consolidado no século XIX, mas ainda impregnado no século XX e XXI (SANTOS, 1988).

O pensamento cartesiano supervaloriza os procedimentos metodológicos simplificadores, promovendo uma visão reducionista do ser e do saber. Para Ferreira (2014),

\footnotetext{
O século XX manteve a tendência do XIX, fortemente influenciado pelo método cartesiano - a separação entre mente e matéria e a divisão do conhecimento em campos especializados em busca de uma maior eficácia. Essa forma de organizar o pensamento levou a comunidade científica a uma mentalidade reducionista na qual o homem adquire uma visão fragmentada não somente da verdade, mas de si mesmo, dos seus valores e dos seus sentimentos (FERREIRA, 2014, p. 34).
}

Esse autor relata que essa fragmentação afeta todas as áreas do conhecimento, limitando a percepção da totalidade, e com a educação não seria diferente. A partir dela que se estabelece a cisão entre teoria e prática pedagógica e a dicotomia entre o trabalho docente e a pesquisa (FERREIRA, 2014).

Essa visão dualista do homem para Leite (2012) tem como efeito o impedimento da compreensão do homem em sua totalidade e, consequentemente, desconsidera a importância da subjetividade no processo de ensino e aprendizagem. Portanto, para o autor é inegável a influência secular da concepção dualista nas práticas das instituições educacionais: herdamos uma concepção segundo a qual o trabalho educacional envolve e deve ser dirigido, essencialmente, para o desenvolvimento dos aspectos cognitivos, centrados na razão, sendo que a afetividade não deve estar envolvida nesse processo. Neste sentido, a formação de professores centrou-se no desenvolvimento da dimensão racional cognitiva em detrimento da dimensão afetiva. Nisso resulta um ensino conservador, descontextualizado e fragmentado em que teoria e prática não estão integradas. 
Ao contrário dessa concepção dualista Behrens (2003) afirma que a formação de professores deve ter como pressuposto central a "transformação social. Para tanto, instiga o diálogo e a discussão coletiva como forças propulsoras de uma aprendizagem significativa" que contemple a cooperação e a participação crítica e reflexiva dos alunos e professores. Busca-se também a "superação da fragmentação do conhecimento, o resgate do ser humano em sua totalidade [...] levando à formação de um profissional, humano, ético e sensível" (BEHRENS, 2003, p.151). Completando as bases dessa interconexão, a autora defende o ensino com pesquisa para superar a tendência à reprodução do conhecimento. Behrens (2003, p. 151) considera a pesquisa "princípio educativo e, portanto, o aluno e professor tornam-se pesquisadores e produtores dos seus próprios conhecimentos". O conhecimento não chega pronto aos professores, está em constante construção. Ele é ressignificado de acordo com a realidade vivenciada na sua atividade docente.

Para Freire (1980), a conscientização é construída no contexto da ação-reflexão, ou seja, não pode existir fora da práxis. Já que conscientização envolve ação, e isto implica em tomar posse da realidade por diversos ângulos. É a partir da reflexão sobre seu contexto, do comprometimento, das decisões, que os homens e mulheres se constroem a si mesmos e chegam a ser sujeitos, chegam a ser autônomos. O ser humano percebe sua temporalidade, reconhece que não vive num eterno presente, que é histórico. Também se reconhece em relação com outros seres e com a própria realidade. A realidade com o seu devir e as relações que estabelece impõe ao ser humano desafios. As respostas dadas a esses desafios não mudam apenas a realidade, mas mudam o próprio homem, "no ato mesmo de responder aos desafios que lhe apresenta seu contexto de vida, o homem se cria, se realiza como sujeito, porque esta resposta exige dele reflexão, crítica, invenção, eleição, decisão, organização, ação" (FREIRE, 1980, p. 37). Assim o homem não se adapta apenas à realidade, ele a configura, e na práxis configuradora se constrói como homem.

Souza (2012) afirma que o ato educativo tem como base a multidimensionalidade e a contextualização e deve superar a fragmentação e os "reducionismos dos saberes" questionando estereótipos cognitivos. Nesse contexto, defende ser necessário refletir a formação docente, valorizando a subjetividade numa concepção sistêmica e interativa. A dimensão da subjetividade precisa ser abordada nos cursos de formação de professores. Para Souza (2012) nos 
cursos de formação ainda prevalece a ideia de dicotomia entre o cognitivo, o afetivo e o social e enfatiza:

é premente que se deixe de ignorar a indissociabilidade dos aspectos afetivos, dos sentimentos, da cognição. Será necessário colocar em destaque no processo formativo as tramas da intersubjetividade, dos valores inerentes à relação docente, de maneira a preservar na sua integridade o lado humano de seus sujeitos (SOUZA, 2012, p. 169).

Nessa perspectiva de formação é possível que o professor se interrogue sobre sua prática, sendo capaz de abandonar uma ação baseada no suposto poder dos métodos e das técnicas, redimensionando a ação educativa. Para as autoras as relações entre experiências de vida do professor, pessoal e profissional, são aspectos determinantes na constituição de sua prática docente. $\mathrm{O}$ reconhecimento da subjetividade na formação docente interfere diretamente no processo de reflexão sobre a práxis e no engajamento ético do sujeito no campo educativo.

Para que a subjetividade seja abordada no processo formativo, visando a formação do professor em sua totalidade, é imprescindível que todo o processo esteja baseado na dialogicidade, na cooperação, por meio de conhecimentos compartilhados. $\mathrm{O}$ processo formativo deve ser construído num espaço de debates constantes, de negociações e de representações da realidade que incluam a subjetividade dos seus agentes.

Sendo a dialogicidade essencial ao processo educativo, é imprescindível que a formação de professores também seja construída com essa característica. Um projeto formativo assim concebido supõe mudanças pedagógicas e didáticas profundas no processo de formação de professores onde:

o processo formativo deve-se voltar à construção democrática, à criatividade; à participação, à abertura da universidade ao diálogo com outros saberes, culturas e tradições, para poder superar as limitações dos paradigmas científicos tradicionais. Seus estudos também inspiram programas que respeitam mais a diversidade e a igualdade, construindo novas subjetividades na teoria e na prática (SOUZA, 2012, p. 165).

Para Freire (2005), este diálogo é um instrumento para emancipação humana que deve ser desenvolvido com afetividade em sua essência. O diálogo não pode existir sem um compromisso afetivo pelo mundo e pelos homens. Conforme enfatiza Souza (2009, p. 147), a importância da relação pedagógica que valoriza o 'entre' e ressalta que "o espaço de diálogo e de ressonância 
'entre' a outra cultura e o 'eu' é uma exigência do ser vivo". O 'entre' "expressa o espaço aberto onde o 'eu' se encontra consigo mesmo, com o outro e com o mundo". Esse espaço multidimensional deve ser construído a cada instante para que o diálogo possa acontecer no processo formativo.

Maturana (2009, p. 19) defende que a experiência de aceitação do "outro como legítimo outro" abre possibilidades de condutas, entre elas a confiança, a escuta, o respeito e a cooperação. Dentro desta concepção, a aceitação do "outro como legítimo outro" se funda na aceitação da diferença, e esta ética é refletida na preocupação com as consequências de nossas ações sobre os outros.

Ainda sobre as relações interpessoais, Masseto (1998, p. 14) afirma que o processo de formação de professores que assume uma dimensão coletiva promotora do diálogo e que valorize a manifestação de aspectos pessoais dos discentes, abre espaço para que sejam expressos e trabalhados aspectos afetivo-emocionais, promovendo o "crescente conhecimento de si mesmo, dos diferentes recursos que possui, dos limites existentes, das potencialidades a serem otimizadas". Admitir a presença dessa dimensão na formação de professores significa compreender a possibilidade de se aperfeiçoar características pessoais como o respeito, a cooperação, a competitividade, a solidariedade, entre outros.

Paulo e Almeida (2008) afirmam que formação de professores deve começar pelo reconhecimento da ligação entre o pessoal e o profissional e que os professores em processo formativo devem passar por uma reaprendizagem da escuta de si mesmos, uma vez que não pode ficar de fora da formação profissional o que sentem e o que são. A esse respeito, Almeida, (2002) refere como imprescindível o uso do dispositivo da escuta na formação de professores para que lhes seja possibilitada a criação ou (re)criação de um elenco próprio de significações acerca do ato educativo, ou seja, para que o professor possa atribuir novos sentidos à transmissão e à mediação do conhecimento, assim como se interrogar sobre os efeitos de sua prática no aprendizado dos seus alunos.

Uma formação de professores que admite e trabalhe a subjetividade dos discentes permite a estes a compreensão do homem como um ser integral. Superando a visão dicotômica de homem "assume-se que as dimensões afetiva e cognitiva são indissociáveis no processo de desenvolvimento humano" (GAZOLI; LEITE, 2011, p. 23). Essa nova concepção integra as dimensões afetiva e cognitiva explicitando a existência de uma relação íntima entre o ambiente social e os processos afetivos e cognitivos. Esse aspecto interfere na formação dos futuros professores. Estes passam a também considerar a 
dimensão subjetiva do 'outro' nas suas relações - desenvolvendo a capacidade de observação e interpretação das intenções, desejos e dizeres dos seus alunos - valorizando a subjetividade e compreendendo importância da dimensão afetiva na relação pedagógica.

A partir da leitura dos autores citados compreende-se que a formação de professores deve considerar a subjetividade docente como algo em construção contínua, onde os processos intra e interformativos podem incluir processos de reflexão e autoconhecimento, reconstituindo os itinerários da prática. Assim, pensar a autoformação é começar a pensar a educação de dentro para fora, num percurso de conhecimento e autoconhecimento. Compartilha-se aqui com a ideia de Almeida (2001), de que urge suscitar interrogações e inquietações que retratem e reflitam o ser que se encontra revestido da profissão educativa: o sujeito na pele de professor.

\section{RESULTADOS E ANÁLISE}

Essa seção apresenta os resultados e a discussão da pesquisa de campo. A partir da observação das reuniões da equipe, primeira etapa da pesquisa percebeu-se que a relação estabelecida entre as professoras-bolsistas teve com base a dialogicidade, na cooperação, por meio de conhecimentos compartilhados que incluíam a subjetividade. Nesses momentos os aspectos pessoais eram valorizados e permitiam a expressão e reflexão sobre aspectos afetivo-emocionais das professoras-bolsistas.

O resultado das entrevistas semiestruturadas realizadas com as professoras-bolsistas foi possível perceber a importância da abordagem da subjetividade como propulsora de reflexões sobre si mesmo e a interferência dessas reflexões no processo formativo. A professora-bolsista B relata:

A gente imaginou uma coisa, mas eles (os idosos) chegavam com um intuito e um objetivo. Só no contato com eles que a gente percebeu que tinha essa imagem errada deles: de que estavam completamente alheios ao mundo que os rodeava, como se estivessem parados no tempo. E foi com isso, conversando sobre isso com a equipe que eu vi o quanto é forte essa coisa da sociedade, a gente repete mesmo tendo a informação teórica, mesmo tendo estudado sobre o idoso. Eu fiquei assustada comigo porque imaginava que por ter estudado sobre o idoso já não ia repetir essa visão da sociedade. Mas a gente repete e só se vendo que é possível mudar isso. (Professora-bolsista B) 
Neste relato acima fica evidente que a abordagem da subjetividade contribui com o processo formativo, pois estimula a autorreflexão e a reflexão crítica sobre si mesmo. As professoras-bolsistas desenvolvem maior consciência sobre si mesmo, percebendo como reproduzem estereótipos sobre o idoso presentes na cultura capitalista ocidental. Trata-se de uma experiência colaborativa e dialógica, coletivamente significativa e ao mesmo tempo individualmente formadora. Para Nóvoa (1992) não há aprendizagem sem experiência e sem uma reflexão pessoal e autobiográfica, em que a autorreflexão tem sentido formador estabelecendo uma reciprocidade entre a cognição e afetividade, aspectos objetivos e subjetivos, a identidade profissional e a identidade pessoal.

No processo formativo desenvolvido com a estrutura do LIM/LIFE percebe-se a valorização da prática no processo formativo e sua decorrente reflexão é um componente constitutivo da formação, como afirma Ferreira (2014). Nota-se, também, os princípios da formação reflexiva apontados por Moura Filho (2011) como o caminho trilhado para que a formação de professores integre a dinâmica teoria/prática. Relata a professora-bolsista A:

\footnotetext{
Quando foi começar as oficinas a gente ficava insegura esperando o idoso chegar e sem saber como seria, quem seria aquele idoso. Acho que a gente foi construindo nessa prévia uma imagem do que seria o idoso que a gente iria atender. Então a gente ficava insegura, nem imaginava quem eram as figuras que iam aparecer. Esse primeiro contato foi interessante porque a gente imaginou que os idosos chegariam meio que passivos e que a gente iria ensinar e pronto. Imaginava que eles não tinham noção de nada. Daí chega um idoso que sabe muito bem o que quer aprender e pra que quer aprender, e daí a gente se surpreendeu com isso. Logo depois do primeiro encontro a gente conversou (com a equipe) e percebi que essa insegurança faz parte mesmo. Depois dessa conversa eu vi que essa coisa da gente se surpreender acontece porque fiquei presa a uma imagem que fiz do idoso e isso não é a realidade. É só vendo quem é o aluno real que dá pra saber quem ele é e saber como agir. Parece que a gente fica sem chão porque está acostumado a ter a segurança de um planejamento a seguir e daí você ter que agir a partir do que o aluno traz faz a gente ficar meio perdida. A gente teve que reorganizar o que é ensinar, teve que mudar nossa forma de planejar e agir. (Professora-bolsista A)
}

Nesse excerto percebe-se a interferência da fragmentação do conhecimento ainda presente nos cursos de formação de professores e como essa visão dualista limita a percepção da realidade. Além disso, impacta na prática docente resultando em um ensino descontextualizado e fragmentado, em que teoria e prática não estão integradas. Paulo e Almeida (2008) afirmam que o reconhecimento 
da subjetividade na formação docente permite que o professor se interrogue sobre a sua prática sendo capaz de abandonar o poder suposto dos métodos e das técnicas redimensionando a ação educativa. Sobre romper com essa perspectiva de ensino tradicional a professora-bolsista $B$ relata:

\begin{abstract}
Quando foi começar as oficinas eu tava muito retraída e incomodada com o fato de estar na posição de ensinar, ainda mais pessoas mais velhas que eu e que já tinham tanta experiência de vida. Foi com as discussões da equipe, com a reflexão do grupo que a gente percebeu que isso vinha porque eu ainda pensava dentro de uma perspectiva de ensino tradicional. De que eu tinha que me colocar de forma superior a eles pra poder ensinar. E eu não me sentia em condições de estar acima deles, como se soubesse mais que eles. Isso mexeu comigo e me fez mudar de lugar na relação com eles. Isso fez que eu fosse mais aberta na relação com eles, perdi o medo de me colocar como pessoa e também de perceber como eles são. (Professora-bolsista B)
\end{abstract}

Nesse relato fica evidente o processo de descoberta e enfrentamento de si mesmo, descobrindo-se como professora a partir das reflexões suscitadas pela abordagem da subjetividade na formação docente. O reconhecimento da ligação entre o pessoal e o profissional percebido no relato acima reforça o processo de escuta de si mesmo. Esse processo de autoconhecimento interfere diretamente no processo de reflexão sobre a práxis (PAULO e ALMEIDA, 2008).

$\mathrm{Na}$ experiência formativa da "Ciranda Digital da Cidadania" a reflexão sobre a prática não se limitou à dimensão técnica e teórica, envolvendo aspectos pessoais do professor em formação, como suas relações interpessoais, sua afetividade, sua subjetividade. Para tanto, foi imprescindível o uso da escuta (ALMEIDA, 2002) nesse processo para que fosse possível a significação ou ressignificação do ato educativo. Ou seja, para que as professoras-bolsistas pudessem atribuir novos sentidos à mediação do conhecimento, assim como se interrogar sobre os efeitos de sua prática no aprendizado de seus alunos. A professora-bolsista relata:

Conversar sobre como eu me sentia no primeiro contato com o idoso me ajudou a perceber como eu carregava preconceitos sobre o idoso. É como se as perguntas sobre os nossos sentimentos levassem a gente a se perceber. Era isso mesmo. Essas conversas faziam a gente refletir e perceber melhor as nossas ações. (Professora-bolsista A)

A partir desse relato é possível refletir sobre o papel do formador docente, em que, como afirma Dominicé (1990, apud PAULO; ALMEIDA, 2008), seria o de 
servir de mediador entre o professor em formação, o objeto de aprendizagem e a análise das situações vividas. Na experiência desta pesquisa é possível identificar essa metodologia de formação por meio de reflexão/introspecção. Os conteúdos subjetivos eram abordados e refletidos em uma interpretação conjunta, entre professoras-bolsistas e coordenação, possibilitando uma posterior reconstrução dos modos de ser e fazer. Esse fato também é visível no relato abaixo:

Tinha tido um encontro da pesquisa que a gente tinha falado sobre perceber o aluno, daí no dia seguinte faço o primeiro atendimento de uma idosa e saí explicando o que ela tinha dito que queria saber. Demorou um tempo para que eu percebesse que ela não sabia ler. Eu fiquei muito mal com isso. Foi conversando sobre isso com a equipe que eu superei e percebi que não adianta só a teoria, a técnica, e sim ver o aluno, a pessoa, e isso era uma dificuldade que eu tinha. A gente não aprende isso em livro. Tive que enfrentar o meu erro para ver que era uma dificuldade minha. (Professora-bolsista B)

Neste relato percebe-se não só a presença do dispositivo escuta (ALMEIDA, 2002) como também a presença da metodologia de formação por meio da reflexão/introspecção. Além disso, nota-se o que Freire (2005) chamou de valorização do 'entre' nos agentes formativos, em que se estabelece uma reconstrução conhecimento que vai além do conteúdo disciplinar. Souza (2009) corrobora com esse pensamento ao afirmar que é uma construção coletiva que possibilita emergir o 'entre', a realidade dos participantes do processo formativo. Isso permite ser elaborado novos conteúdos como a aceitação do princípio dialógico, em que sujeitos "aprendem com os outros, em cooperação com os outros, para si e para os outros" (SOUZA, 2009, p.147).

$\mathrm{Na}$ experiência formativa investigada por este estudo foi possível perceber que o processo de formação de professores que assume uma dimensão coletiva, promotora de diálogo e que valorize e estimule a manifestação de aspectos pessoais dos discentes, abre espaço para que sejam trabalhados aspectos afetivos-emocionais, promovendo o "crescente conhecimento de si mesmo, dos diferentes recursos que possui, dos limites existentes, das potencialidades a serem otimizadas" (MASSETO, 1998, p. 14). O relato da professora-bolsista D exemplifica:

Foi sendo perguntada como me sentia que eu percebi que eu ficava ansiosa para o idoso aprender o que eu queria. Não entendia que era possível ele não querer aprender alguma coisa. Depois que vi que isso era um problema meu e não dele. (Professora-bolsista D) 
Este relato evidencia que a abordagem da subjetividade docente possibilita a reflexão e o consequente autoconhecimento. Esse movimento de compreensão das diferenças entre 'si mesmo' e o 'outro' possibilita a aceitação do "outro como legítimo outro" e se reflete na preocupação com as consequências das suas ações sobre os outros (MATURANA, 2009). Esta dimensão ética move a possibilidade de se aperfeiçoar características pessoais como o respeito, a cooperação, a solidariedade, entre outros (MASSETO, 1998). Além desse aspecto, fica claro que, para que o professor tenha a capacidade de compreender a subjetividade do aluno é necessário que o tenha lidado com a sua subjetividade no seu processo formativo.

$\mathrm{Na}$ experiência desta pesquisa ficou evidente as vantagens da abordagem da subjetividade na formação docente. A prática do projeto desenvolvido com a estrutura do LIM/LIFE mostra que é possível desenvolver uma formação de professores em que a indissociabilidade dos aspectos afetivos, dos sentimentos e da cognição estejam efetivamente presentes.

Nota-se a importância da integração ensino-pesquisa-extensão para a formação de professores, como afirmam Ducatti-Silva e Zanon (2014), por romper com o hiato entre teoria e prática transformando o momento de formação em espaço de produção de conhecimento. Desta forma, o professor em formação se reconhece como "aluno" para ser sujeito da sua prática pedagógica. $\mathrm{O}$ relato da professora-bolsista $\mathrm{C}$ exemplifica:

Eu aprendi a ser professora, melhorei como pessoa. O que vivemos no projeto vai muito além da teoria. Hoje eu consigo entender o que eu aprendi nas disciplinas do curso. É como se tivesse tirado um véu que me impedia de entender direito, de forma mais profunda. Hoje eu sei na prática o que a teoria fala. (Professora-bolsista C)

Nesse relato é possível perceber como a identidade profissional tem relação de reciprocidade com a identidade pessoal. A abordagem e reflexões sobre a subjetividade/objetividade, afetividade/cognição valorizadas e estimuladas pela coordenação do projeto promovem a integração teoria-prática. Essa experiência bem-sucedida do LIM/LIFE/UEG torna explícito de que é possível uma formação de professores que propicie a construção do conhecimento integrando todas as dimensões - social, histórica, cultural e afetiva; que parta da realidade dos envolvidos - seus conhecimentos prévios, inquietações, atitudes, sentimentos, valores; promovendo uma aprendizagem significativa que resulta em novas ações individuais e coletivas. Desde que se proponha uma 
experiência de formação dialógica propulsora de reflexões e que repense a formação de professores destacando a necessidade de abordar a subjetividade no processo formativo. É premente que o processo formativo desvinculado das atividades de pesquisa e extensão - que são a maioria nos cursos de formação - encontre alternativas para superar a dissociação teoria-prática, a tendência de reprodução do conhecimento e a fragmentação de saberes que impedem a compreensão do homem na sua totalidade.

\section{CONSIDERAÇÕES FINAIS}

A partir desse estudo percebe-se a importância da universidade e do seu compromisso com a indissociabilidade ensino-pesquisa-extensão para a formação de professores. A formação das professoras-bolsistas realizada na UEG a partir do tripé ensino-pesquisa-extensão caracterizou-se como um momento privilegiado de formação, promovendo um processo formativo que superou a fragmentação do conhecimento ao valorizar a subjetividade e a prática pedagógica como componente formador, rompendo com a visão dicotômica teoria-prática. A integração teoria-prática se deu por meio da dialogicidade, da reflexão crítica e colaborativa que incluíam a subjetividade das tutoras. Essa formação presente na experiência do projeto de extensão desenvolvido a partir do LIM/LIFE/UEG promoveu uma (re)construção do conhecimento integrando todas as suas dimensões, fornecendo subsídios para alterar a ação das professoras-bolsistas.

As reflexões incitadas por meio do diálogo e da discussão coletiva sobre as experiências objetivas e subjetivas das tutoras possibilitaram a consciência, avaliação e questionamento de si mesmo, de sua prática, dos outros e de conhecimentos científicos. Disso resultou uma aprendizagem integradora, contribuindo para a formação de profissionais mais sensíveis à subjetividade do aluno. Portanto, conclui-se que a partir do estudo desse momento privilegiado de formação docente das professoras-bolsistas do projeto desenvolvido com a estrutura do LIM/LIFE/UEG, reafirma-se a necessidade da formação de professores romper com a visão dicotômica entre teoria e prática pedagógica que ainda perdura nos cursos formativos. 


\section{REFERÊNCIAS}

ALMEIDA, S. F. C. de. Psicanálise e educação: revendo algumas observações e hipóteses a respeito de uma (im)possível conexão. In: KUPFER, M. C. \& LAJONQUIÈRE, L. (Orgs.). Psicanálise infância educação. Anais do III Colóquio do LEPSI. São Paulo: USP, 2002. p.95-106.

BEHRENS, M. A. Projetos de aprendizagem colaborativa num paradigma emergente. In: BEHRENS, M. A.; MORAN, J. M.; MASETTO, M. Novas tecnologias e mediação pedagógica. 5. ed. Campinas: Papirus, 2003.

BRASIL. Constituição (1988). Constituição da República Federativa do Brasil: Brasília, DF: Senado, 1988.

DUCATTI-SILVA, K. C.; ZANON, D. P. As contribuições dos projetos de ensino, pesquisa e extensão para formação inicial e continuada de professores. In: GRUPO DE ESTUDOS E PESQUISAS EM POLÍTICA EDUCACIONAL E AVALIAÇÃO, Ponta Grossa, 2014. FERREIRA, J. de L. A Complexa relação entre Teoria e Prática Pedagógica. In: Jacques de Lima Ferreira. (Org.). Formação de Professores: teoria e prática pedagógica. 1. ed. Petrópolis, Rio de Janeiro: Vozes, v. 1, p. 33-49. 2014.

FREIRE, P. Pedagogia da autonomia: saberes necessários e prática educativa. São Paulo: Paz e Terra. 1996.

Pedagogia do oprimido. Rio de Janeiro: Editora Paz e Terra, 2005.

Extensão ou comunicação? 5. ed. Rio de Janeiro: Paz e Terra, 1980.

GARCÍA, C. M. Formação de professores: para uma mudança educativa. Portugal: Porto Editora, 1999.

GAZOLI, D. G. D; LEITE, S. A. S. Educação de jovens e adultos: a dimensão afetiva na mediação pedagógica. In: CONGRESSO NACIONAL DE PSICOLOGIA ESCOLAR E EDUCACIONAL, 10., 2011, Maringá. Anais... Maringá: Universidade Estadual de Maringá. Disponível em: http://www.abrapee.psc.br/xconpe/trabalhos/1/113.pdf. Acesso: 2 fev. 2015.

MASSETO, M. T. (Org). Docência na universidade. Campinas, SP: Papirus, 1998.

MATURANA, H. R. Emoções e linguagem na educação e na política. Belo Horizonte: UFMG, 2009.

MOITA, F. M. G. S. C; ANDRADE, F. C. B. Ensino-pesquisa-extensão: um exercício de indissociabilidade na pós-graduação. Revista Brasileira de Educação, v. 14, n. 41, maio/ ago. 2009.

MOURA FILHO, A. C. L. Basta de clamarmos inocência: a formação reflexiva do professor contemporâneo de línguas. In: SILVA, K. A. et al. A formação de professores de línguas: novos olhares. v. 1. São Paulo: Pontes, 2011. p. 49-72. 
NOVOA, Antonio. Os professores e as histórias de suas vidas. In: NÓVOA, A. (Org.). Vidas de professores. Porto: Porto Editora, 1992.

PAULO, T.S; ALMEIDA, S.F.C. Formação de professores: subjetividade e práticas docentes. In: FORMAÇÃO DE PROFISSIONAIS E A CRIANÇA-SUJEITO, 7., 2008, São Paulo, 2008.

SILVA, Y. F. O (2014). Universidade e desenvolvimento local: o caso da Universidade Estadual de Goiás. [Tese] Doutorado em Políticas Públicas, Estratégias e Desenvolvimento) Rio de Janeiro: Instituto de Economia, Universidade Federal do Rio de Janeiro. (UFRJ)

SOUZA, R. C. C. R. Universidade: Inovações pedagógicas e complexidade. In: GUIMARÃES, V. S. Formação e Profissão docente: cenários e propostas. Goiânia: Editora PUC, 2009.

Formação de Professores: tempos de vida, tempos de aprendizagem. In: MAGALHAES, S. M. O. (Org). Formação de professores: elos da dimensão complexa e transdisciplinar. Goiânia: Editora da PUC Goiás, 2012. 